\title{
Late reconstruction of extensive orbital floor fracture with a patient-specific implant in a bombing victim
}

\author{
Maximiliaan Smeets ${ }^{1,2}$, Robin Snel ${ }^{1,2}$, Yi Sun ${ }^{1,2}$, Titiaan Dormaar ${ }^{1,2}$, Constantinus Politis ${ }^{1,2}$ \\ ${ }^{1}$ OMFS-IMPATH Research Group, Department of Imaging and Pathology, Faculty of Medicine, KU Leuven, \\ ${ }^{2}$ Department of Oral and Maxillofacial Surgery, University Hospitals Leuven, Leuven, Belgium
}

\begin{abstract}
J Korean Assoc Oral Maxillofac Surg 2020;46:353-357)
Fractures of the orbital floor and walls are among the most frequent maxillofacial fractures. Virtual three-dimensional (3D) planning and use of patientspecific implants (PSIs) could improve anatomic and functional outcomes in orbital reconstruction surgery. The presented case was a victim of a terrorist attack involving improvised explosive devices. This 58-year-old female suffered severe wounds caused by a single piece of metal from a bomb, shattering the left orbital floor and lateral orbital wall. Due to remaining hypotropia of the left eye compared to the right eye, late orbital floor reconstruction was carried out with a personalised 3D printed titanium implant. We concluded that this technique with PSI appears to be a viable method to correct complex orbital floor defects. Our research group noted good aesthetic and functional results one year after surgery. Due to the complexity of the surgery for a major bony defect of the orbital floor, it is important that the surgery be executed by experienced surgeons in the field of maxillofacial traumatology.
\end{abstract}

Key words: Prostheses and implants, Orbital fracture, Surgical traumatology, Three-dimensional printing [paper submitted 2018. 7. 13 / revised 2018. 8. 30 / accepted 2018. 8. 31]

\section{Introduction}

Surgical reconstruction of orbital wall and floor defects is often very challenging due to the complexity of the anatomical region involved and the limited intraoperative view. Diplopia, enophthalmos, visual acuity disturbance, and infraorbital and optical nerve injuries are potential complications of orbital floor and wall fracture surgery. Reconstruction is also on a technical level demanding surgeons because it can result in paraesthesia and esthetical dissatisfaction, especially when there is a major bony defect of the floor of the orbit, as in this case. The aim of reconstruction is to restore the orbit in all three dimensions. The orbital floor can be reconstructed using a variety of implant materials. Biological materials

\section{Maximiliaan Smeets}

Department of Oral and Maxillofacial Surgery, University Hospitals of Leuven, Campus Sint-Rafaël, Kapucijnenvoer 33, BE-3000 Leuven, Belgium TEL: +32-0-16-33-24-62

E-mail: smeetsmaximiliaan@gmail.com

ORCID: https://orcid.org/0000-0003-0530-1315

(c) This is an open-access article distributed under the terms of the Creative Commons Attribution Non-Commercial License (http://creativecommons.org/ licenses/by-nc/4.0/), which permits unrestricted non-commercial use, distribution, and reproduction in any medium, provided the original work is properly cited.

Copyright (C) 2020 The Korean Association of Oral and Maxillofacial Surgeons. All rights reserved. offer the potential advantage of better biocompatibility but come at the cost of donor-site morbidity. Currently, titanium reconstruction plates or mesh are the materials of choice due to their availability, ease of contouring, biocompatibility, resistance to corrosion, and low susceptibility to infections ${ }^{1}$. However, they are not easy to place, especially with deep orbital fractures. Since 2006, custom-made titanium implants designed using computer-assisted planning and manufacturing $(\mathrm{CAD} / \mathrm{CAM})$ have been used for reconstruction of orbital fractures.

The objective of the present case report was to illustrate our methodology to reconstruct complex orbital trauma with a three-dimensional (3D) printed patient-specific implant (PSI) in an enucleated orbit.

\section{Case Report}

A 58-year-old female was sent to the Department of Oral and Maxillofacial Surgery at the University Hospitals Leuven for treatment of a severe orbital trauma, caused by the 2016 Brussels bombings.(Fig. 1) She was at Brussels Airport at the time the bombs went off. A piece of shrapnel penetrated the left orbital floor, the left eye, and the sphenoidal bone of 
the lateral orbital wall, with a final position in contact with the left temporal lobe.(Fig. 2. B) The shrapnel was removed by a frontotemporal incision, which visualised a metal object of two centimetres just medial to the temporal muscle. (Fig. 2. A) In addition to the orbital lesions, a haemorrhagic contusion of the frontal and anterior temporal lobe and a perforated eardrum on the left side were noted. During the same procedure, enucleation of the left eye was performed due to irreparable corneal damage and complete scleral rupture. The soft tissue laceration was closed, and the nasolacrimal duct was restored.(Fig. 2. C) An acrylic eye implant was inserted into the orbit to maintain orbital structural integrity. In the following months after surgery, enophthalmos and hypotropia of the prosthesis with a deep supratarsal fold of the upper eyelid were noted, and a computed tomography (CT) scan showed posterolateral dislocation of the prosthesis with an inferior position compared with the unharmed eye, an indication for secondary surgery.(Fig. 3. A) The goal of secondary reconstruction was to restore symmetrical globe position to recover aesthetics. The interval between trauma and surgi-

\begin{tabular}{|l|l|}
\hline March 2016 & April 2017 \\
\hline \hline $\begin{array}{l}\text { Brussels attacks } \\
\text { - Shrapnel removal } \\
\text { - Enucleation of the left eye } \\
\text { - Soft tissue laceration } \\
\text { closure } \\
\text { - Insertion acrylic eye } \\
\text { implant }\end{array}$ & $\begin{array}{l}\text { Surgical } \\
\text { reconstruction of } \\
\text { orbital floor fracture } \\
\text { with patient-specific } \\
\text { implant. }\end{array}$ \\
\end{tabular}
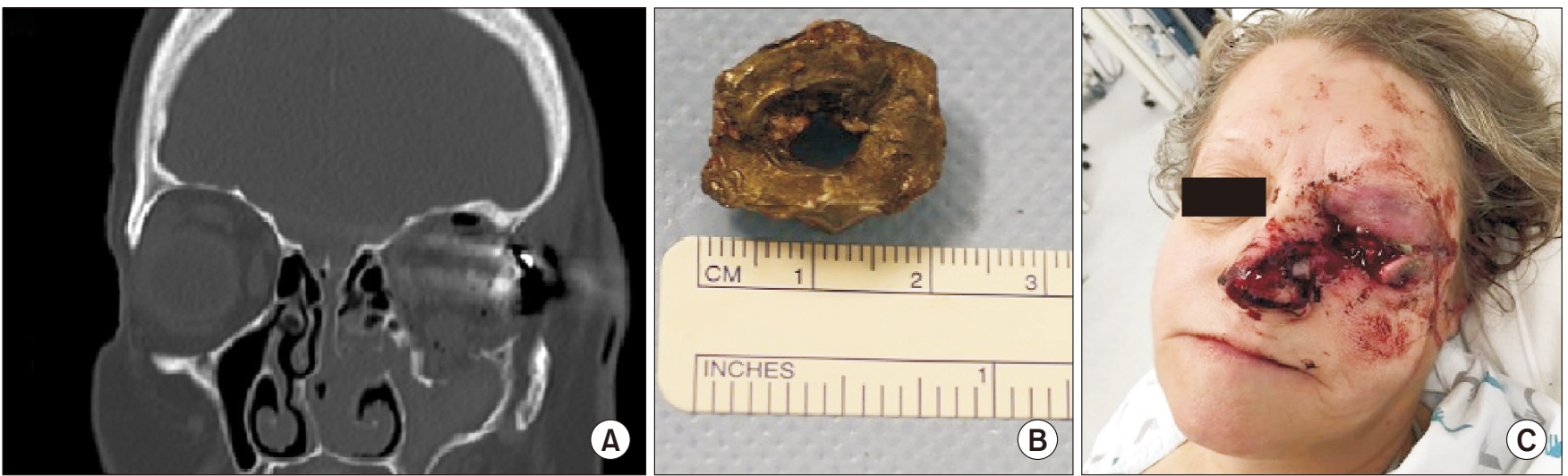

Fig. 1. Overview of the overall treatment flow.

Maximiliaan Smeets et al: Late reconstruction of extensive orbital floor fracture with a patient-specific implant in a bombing victim. J Korean Assoc Oral Maxillofac Surg 2020

Fig. 2. Status immediately after the attacks. A. Initial computed tomography image with shattering of orbital bony structures. B. Shrapnel obtained after surgical removal. C. Facial lacerations.

Maximiliaan Smeets et al: Late reconstruction of extensive orbital floor fracture with a patient-specific implant in a bombing victim. J Korean Assoc Oral Maxillofac Surg 2020
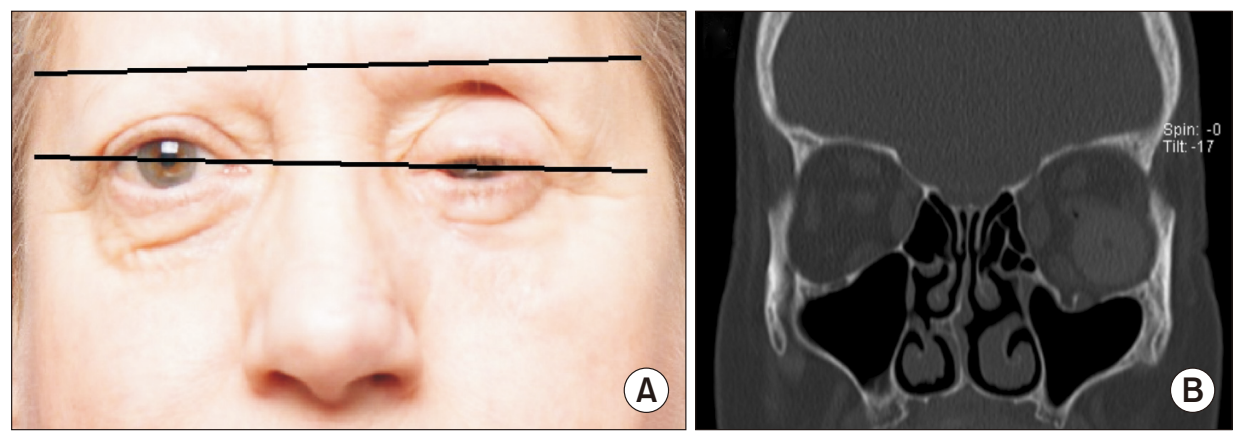

Fig. 3. Status just before surgery and one year after the attacks. A. Interpupillary lines. B. Computed tomography image showing the residual defect of the orbital floor.

Maximiliaan Smeets et al: Late reconstruction of extensive orbital floor fracture with a patient-specific implant in a bombing victim. J Korean Assoc Oral Maxillofac Surg 2020 
cal enophthalmos correction was 1.1 years. The extent of the bone defect was assessed on preoperative CT scans.(Fig. 3. B)

To generate a 3D image, the preoperative CT scan (thinsection $\leq 1 \mathrm{~mm}$ ) was first imported with the use of Mimics software (Materialise, Leuven, Belgium).(Fig. 4. A-C) A stereolithographic model of the orbit was produced.(Fig. 4. D, 4. E) A 3D model was then imported into 3-matic software (Materialise), in which a customized orbital floor reconstruction plate neatly fit the patient's anatomic model. Afterward, the designed orbital floor reconstruction plate was exported in STL format, and a titanium mesh PSI (Ti6Al4V Grade 23) was 3D-printed by Layerwise (3D Systems, Leuven, Belgium; as stated by Bertol et al. ${ }^{2}$ ). The dimensions of the designed mesh were $32 \mathrm{~mm}$ by $32 \mathrm{~mm}$ with a thickness of 0.3 mm.(Fig. 4. B) The goal was to overcorrect the hypotropia to hypertropia of the eye and to use lipofilling to add extra volume to the infraorbital supra osseous tissues. For soft tissue correction, overcorrection of the orbital floor was performed. Preoperatively, there was diminished sensation of the infraand supraorbital nerves. During surgery, a subciliary incision was used to expose the infraorbital rim and the orbital floor. The surgeon opted to make a small modification in the shape of the mesh during surgery to obtain an ideal esthetical result. Consequently, the 3D-printed mesh was inserted into the bony defect of the floor of the orbit, and fixation occurred to the inferior orbital rim with surgical loops on stable bony structures after careful evaluation of the final position of the eye implant. One year after surgery, the patient experiences no residual complaints, except mildly diminished sensation on the left cheek that was present before the reconstructive
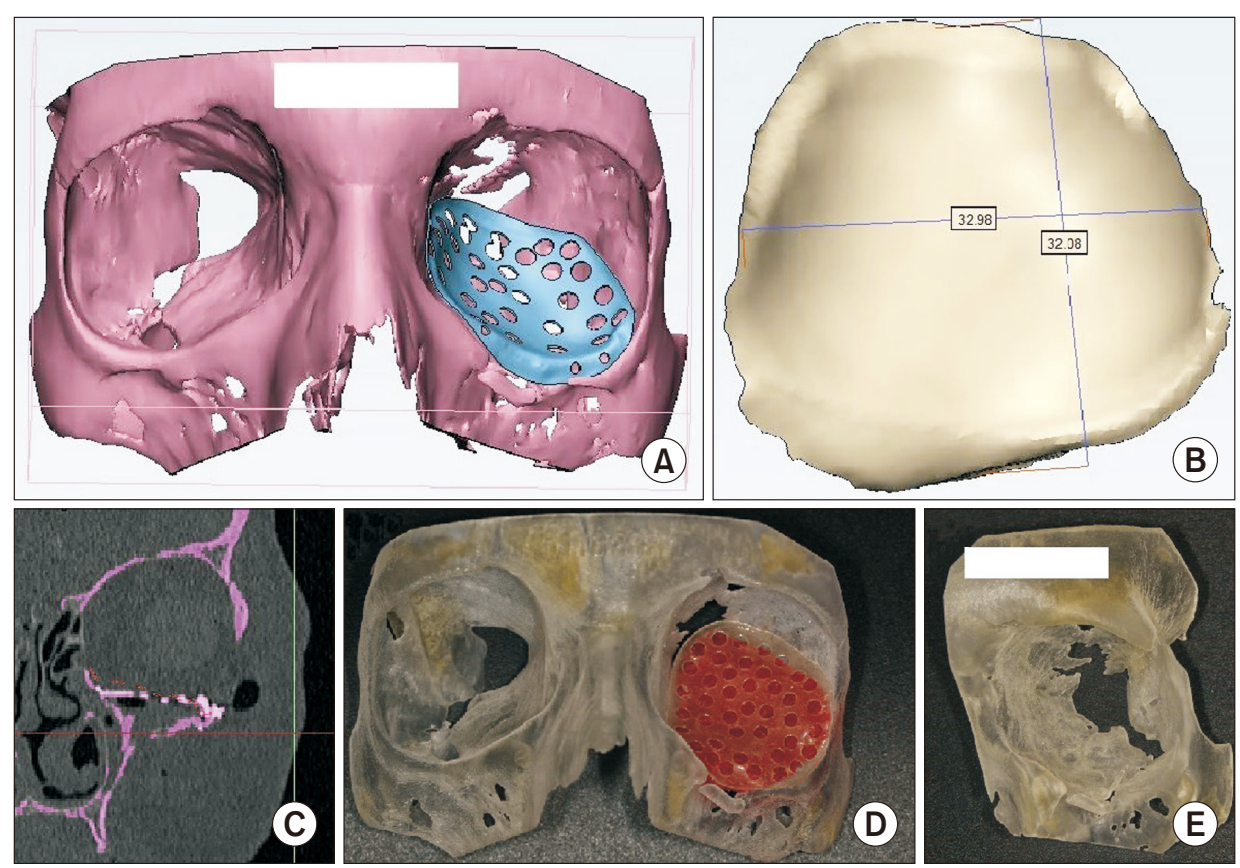

(B)

Fig. 4. Virtual three-dimensional planning. A. First version of the customized orbital floor reconstruction plate. B. Size of the defect in millimetres. C. Virtual position of the reconstruction plate on computed tomography scan. D. The stereolithographic model with a copy of the final titanium reconstruction plate. E. Magnification of the bony defect before surgery.

Maximiliaan Smeets et al: Late reconstruction of extensive orbital floor fracture with a patient-specific implant in a bombing victim. J Korean Assoc Oral Maxillofac Surg 2020
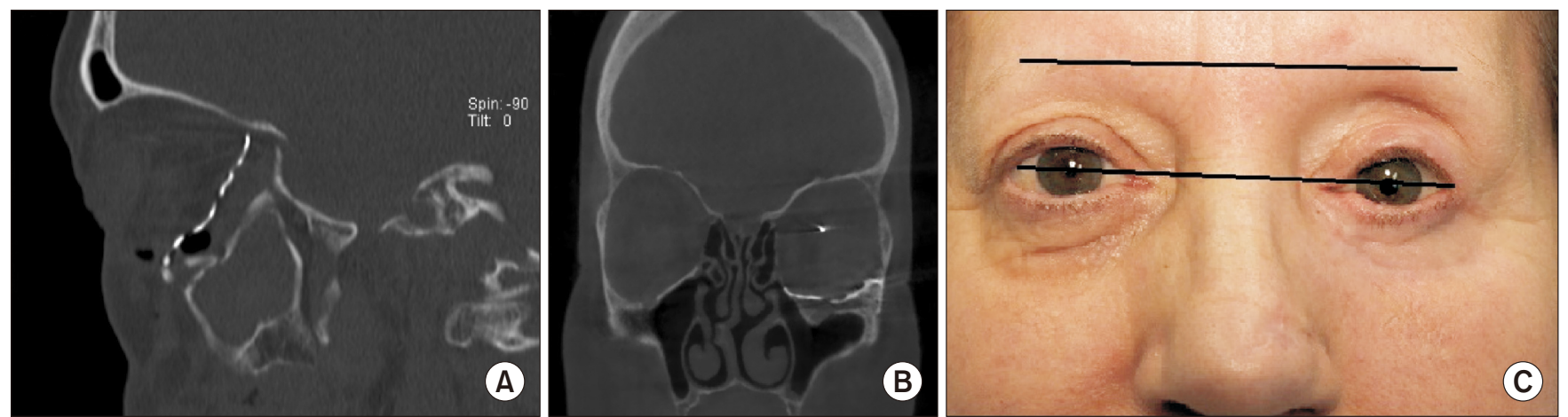

Fig. 5. Status one year after surgery and two years after the attacks. A. Computed tomography (CT) image showing current position of the patient-specific implant. B. CT image showing current status one year after surgery. C. Interpupillary lines one year after surgery. Maximiliaan Smeets et al: Late reconstruction of extensive orbital floor fracture with a patient-specific implant in a bombing victim. J Korean Assoc Oral Maxillofac Surg 2020 
procedure.

Our research group examined the results both on aesthetical outcome, with correction of preoperative hypotropia (Fig. 5. C), and from a functional point of view. The patient reported high satisfaction with the acquired result (Table 1), so no further corrections were planned, although aesthetic surgical procedures are still possible. The variables in Table 1 are based on a study of de Oliveira et al. ${ }^{3}$, which used 10 questions to determine patient satisfaction with orbital implant-supported prostheses. Furthermore, the most recent radiological images showed a stable position of the orbital floor implant.(Fig. 5. A, 5. B)

\section{Discussion}

Severe orbital fractures with large-area wall defects may cause substantial cosmetic damage and functional disorders, including enophthalmos, diplopia, diminished sensation of the infraorbital nerve, retinal trauma, and loss of vision. One of the most challenging aspects of orbital reconstruction is to restore orbital volume. Moreover, late or secondary reconstruction of the orbital region and the midface is more challenging than primary reconstruction because of distorted skeletal anatomic landmarks and late soft tissue changes.

Current literature mentions several materials for 3D-printing. Ideal orbital reconstruction implants are biocompatible, widely available, strong enough to provide orbital support, easily shaped, and radio-opaque. Autologous harvested bone is frequently used for restoration of a bony defect. For nonvascularised bone grafting, for example, both the scapula and iliac crest offer sufficient conformance, although high rates of infection and bone resorption are witnessed ${ }^{4-7}$. However, donor site morbidity and unsure esthetical outcomes can be

Table 1. Satisfaction of the patient ranging from 0-100, with 100 representing the optimal result

\begin{tabular}{lc}
\hline \multicolumn{1}{c}{ Variable } & Satisfaction \\
\hline Appearance & 90 \\
Efficiency in retention & 90 \\
Conspicuousness of the prostheses & 95 \\
Improvement of self-confidence & 95 \\
Ease of placement & 95 \\
Ease of removal & 95 \\
Ease of cleaning & 95 \\
No limitations to activities & 90 \\
Absence of discomfort & 95 \\
Recommendation to others & 95 \\
\hline
\end{tabular}

This questionnaire is based on that of de Oliveira et al. ${ }^{3}$ (Clin Implant Dent Relat Res 2018;20:438-43).

Maximiliaan Smeets et al: Late reconstruction of extensive orbital floor fracture with a patient-specific implant in a bombing victim. J Korean Assoc Oral Maxillofac Surg 2020 avoided with 3D-printed implants, leading to improved anatomical precision, patient-specific modelling, and increased anatomical integrity and aesthetics ${ }^{8}$.

In this case, a 3D-printed titanium personalised mesh was designed with a CAD (computer-assisted device)-based technique. Titanium has some major advantages over other materials: availability, biocompatibility, resistance to corrosion, and low susceptibility to infections ${ }^{1}$. Furthermore, multiple studies reported that use of individualized constructed titanium orbital mesh plates results in a better aesthetic outcome compared with standard reconstruction plates, and titanium mesh is a safe method for orbital floor reconstructions ${ }^{4,6,8-10}$. Computer-assisted preoperative planning by fabricating PSI shortens operating time and decreases intraoperative implant manipulation because no additional bending or adjustment of the implant is needed ${ }^{9,11}$. Moreover, a PSI can compensate for bony deficits and irregularities.

The PSI in this case was quite complex to fit correctly due to the size and shape of the orbital floor defect and the limited intraoperative view. Furthermore, the delay of one year between trauma and surgery led to formation of fibrous tissue which further limited the surgical field. Based on these aspects of the surgical procedure, the research group would like to stress that, if possible, the size of the plate should be minimal. This is based on the findings of Purnell et al. ${ }^{12}$. Nevertheless, our research group is convinced that personalized 3D printing shortens operating time. This conclusion is supported by Zimmerer et al. ${ }^{9}$ and Fan et al. ${ }^{13}$.

This case of a victim of the Brussels attacks shows that a good functional and aesthetic result can be achieved with a $3 \mathrm{D}$-printed titanium mesh in a complex orbital floor and wall defect with reduced operating time. As PSI simplifies reconstruction of orbital floor and wall defects, it should be considered a more accurate alternative to manually bent titanium mesh implants.

\section{ORCID}

Maximiliaan Smeets, https://orcid.org/0000-0003-0530-1315

Robin Snel, https://orcid.org/0000-0002-1243-8806

Yi Sun, https://orcid.org/0000-0001-6981-7658

Titiaan Dormaar, https://orcid.org/0000-0001-9382-2473

Constantinus Politis, https://orcid.org/0000-0003-4772-9897

\section{Authors' Contributions}

M.S. participated in data collection and wrote the manu- 
script. R.S., T.D., Y.S., and C.P. participated in the study design and performed the statistical analysis. M.S. participated in the study design and coordination and helped to draft the manuscript. All authors read and approved the final manuscript.

\section{Consent for Publishing Photographs}

Written informed consent was obtained from the patient for publication of this article and accompanying images.

\section{Conflict of Interest}

No potential conflict of interest relevant to this article was reported.

\section{References}

1. Ellis E 3rd, Messo E. Use of nonresorbable alloplastic implants for internal orbital reconstruction. J Oral Maxillofac Surg 2004;62:87381. https://doi.org/10.1016/j.joms.2003.12.025

2. Bertol LS, Kindlein W Jr, da Silva FP, Aumund-Kopp C. Medical design: direct metal laser sintering of Ti-6Al-4V. Mater Des 2010;31:3982-8. https://doi.org/10.1016/j.matdes.2010.02.050

3. de Oliveira FM, Salazar-Gamarra R, Öhman D, Nannmark U, Pecorari V, Dib LL. Quality of life assessment of patients utilizing orbital implant-supported prostheses. Clin Implant Dent Relat Res 2018;20:438-43. https://doi.org/10.1111/cid.12602

4. Davies JC, Chan HHL, Bernstein JM, Goldstein DP, Irish JC, Gilbert RW. Orbital floor reconstruction: 3-Dimensional analysis shows comparable morphology of scapular and iliac crest bone grafts. J Oral Maxillofac Surg 2018;76:2011-8. https://doi. org/10.1016/j.joms.2018.03.034

5. Ilankovan V, Jackson IT. Experience in the use of calvarial bone grafts in orbital reconstruction. Br J Oral Maxillofac Surg 1992;30:92-6. https://doi.org/10.1016/0266-4356(92)90077-v

6. Zhang WB, Mao C, Liu XJ, Guo CB, Yu GY, Peng X. Outcomes of orbital floor reconstruction after extensive maxillectomy using the computer-assisted fabricated individual titanium mesh technique. J Oral Maxillofac Surg 2015;73:2065.e1-15. https://doi.org/10.1016/ j.joms.2015.06.171

7. Young SM, Sundar G, Lim TC, Lang SS, Thomas G, Amrith S. Use of bioresorbable implants for orbital fracture reconstruction. Br J Ophthalmol 2017;101:1080-5. https://doi.org/10.1136/bjophthalmol-2016-309330

8. Al-Khdhairi OBH, Abdulrazaq SS. Is orbital floor reconstruction with titanium mesh safe? J Craniofac Surg 2017;28:e692-4. https:// doi.org/10.1097/SCS.0000000000003864

9. Zimmerer RM, Ellis E 3rd, Aniceto GS, Schramm A, Wagner ME, Grant MP, et al. A prospective multicenter study to compare the precision of posttraumatic internal orbital reconstruction with standard preformed and individualized orbital implants. J Craniomaxillofac Surg 2016;44:1485-97. https://doi.org/10.1016/ j.jcms.2016.07.014

10. Hwang WJ, Lee DH, Choi W, Hwang JH, Kim KS, Lee SY. Analysis of orbital volume measurements following reduction and internal fixation using absorbable mesh plates and screws for patients with orbital floor blowout fractures. J Craniofac Surg 2017;28:1664-9. https://doi.org/10.1097/SCS.0000000000003730

11. Oh TS, Jeong WS, Chang TJ, Koh KS, Choi JW. Customized orbital wall reconstruction using three-dimensionally printed rapid prototype model in patients with orbital wall fracture. J Craniofac Surg 2016;27:2020-4. https://doi.org/10.1097/SCS.0000000000003195

12. Purnell CA, Vaca EE, Ellis MF. Orbital fracture reconstruction using prebent, anatomic titanium plates: technical tips to avoid complications. J Craniofac Surg 2018;29:e515-7. https://doi. org/10.1097/SCS.0000000000004563

13. Fan B, Chen H, Sun YJ, Wang BF, Che L, Liu SY, et al. Clinical effects of 3-D printing-assisted personalized reconstructive surgery for blowout orbital fractures. Graefes Arch Clin Exp Ophthalmol 2017;255:2051-7. https://doi.org/10.1007/s00417-017-3766-y

How to cite this article: Smeets M, Snel R, Sun Y, Dormaar T, Politis C. Late reconstruction of extensive orbital floor fracture with a patient-specific implant in a bombing victim. J Korean Assoc Oral Maxillofac Surg 2020;46:353-357. https://doi. org/10.5125/jkaoms.2020.46.5.353 